\title{
THE LOSS OF NEURON-SPECIFIC PROTEINS DURING THE COURSE OF WALLERIAN DEGENERATION OF OPTIC AND SCIATIC NERVE ${ }^{1}$
}

\author{
DAVID SOIFER, ${ }^{2}$ KHALID IQBAL, HENRYK CZOSNEK, JOY DE MARTINI, JOHN A. STURMAN, AND \\ HENRYK M. WISNIEWSKI
}

Department of Pathological Neurobiology, Institute for Basic Research in Mental Retardation, Staten Island, New York 10314

\begin{abstract}
To identify axonal proteins which are unique constituents of neurons, the spectrum of detectable proteins of degenerating nerves has been compared with that of intact control nerves from the same animals. Wallerian degeneration was induced in rabbits by unilateral transection of the optic and sciatic nerves. Proteins of nerve homogenates were compared by sodium dodecyl sulfate-gel electrophoresis and by two-dimensional electrophoresis. Four non-myelin proteins disappear from degenerating nerve. These include the three neurofilament proteins (P68, P150, and P200) and a polypeptide with a molecular weight of about 65,000 daltons (P65) which is not associated with filaments.
\end{abstract}

The phenomenon of Wallerian degeneration (Waller, 1850; Joseph, 1973) can serve as an experimental tool for the study of neuron-specific proteins of the nerve. In this process, the parts of the axons distal to a lesion undergo a progressive degeneration during which the axons, followed by the associated myelin, are broken down. When the axon degenerates, axon-specific proteins should disappear, while proteins of such non-neuronal elements as fibrous astrocytes should actually increase as the glial cells proliferate in the degenerating nerve. Several investigators have used experimentally induced Wallerian degeneration in an attempt to identify neuron-specific proteins. Although Dahl and Bignami (1975) reported no difference between degenerated and control rat optic nerves except for myelin proteins, their figures indicated a loss of high molecular weight protein in the course of degeneration. In a preliminary communication (Soifer et al., 1978), we reported several changes in the more prominent proteins of rabbit optic nerve following removal of one eye. These included a loss of the triplet of proteins associated with neurofilaments (Hoffman and Lasek, 1975) and a small decrease in the broad band of material that migrates on sodium dodecyl sulfate (SDS)-polyacrylamide gels with an apparent molecular weight of about 50,000 daltons. In sciatic nerve, which lacks a prominent 50,000-dalton protein (Schlaepfer et al., 1979;

\footnotetext{
${ }^{1}$ We thank Kathryn Mack, Christopher Thompson, and Tanweer Zaidi for their technical assistance and Richard Weed and Ken Wolfson for their assistance with photographic reproduction. This research was supported by the Office of Mental Retardation and Developmental Disabilities of the State of New York and by National Institutes of Health Grant NS 14495.

${ }^{2}$ To whom correspondence should be addressed.
}

Czosnek and Soifer, 1980), Schlaepfer and Micko (1978) found evidence for a loss of the neurofilament proteins in parallel with the degeneration of the axons. A serious problem, relating to the resolution of the gel electrophoresis methods employed, results from the presence of more than one protein with a given electrophoretic mobility. Thus, a decrease in the amount of a given protein band might reflect the disappearance of one of the population of co-migrating proteins. Alternatively, changes in the relative amounts of co-migrating proteins might be masked. With the development of the methods for two-dimensional analysis using isoelectric focusing in the first dimension (O'Farrell, 1975; Scheele, 1975), proteins of similar size could be separated. Since several of the proteins found in nerve have been characterized by twodimensional analysis (Czosnek et al., 1980; Czosnek and Soifer, 1980), it might be possible to identify some of the neuron-specific proteins which disappear during the course of degeneration. Furthermore, we could determine whether the small decrease in P50 reflected the disappearance of one of the several proteins with apparent molecular weights of about 50,000 daltons.

\section{Materials and Methods}

Experimental procedures. New Zealand white rabbits were obtained from New Springville Labs and Penn Dutch Lab Animals and maintained on standard laboratory diet. Anesthesia was initiated with sodium pentobarbital (Nembutal, $75 \mathrm{mg}$ in $1.5 \mathrm{ml}$, i.v.) and maintained with ether for the duration of the surgical procedures. One or two drops of $0.5 \%$ tetracaine hydrochloride were applied to one eye to produce surface anesthesia a few minutes prior to enucleation. The optic nerve was sectioned as close to the eyeball as possible and the eye 
was removed. One sciatic nerve was sectioned above the sciatic notch and the proximal end was sutured away from the distal end to ensure that no regenerating nerves made contact with the degenerating distal nerve. In each animal, the right nerves were sectioned. The uncut nerves served as controls.

After the appropriate times, the animals were killed by cervical section and both optic nerves, from orbit to chiasm, and the tibial branches of both sciatic nerves were removed quickly. A small piece of each was taken for electron microscopy. In the case of sectioned optic nerve, the sample was from the region anterior to the optic chiasm to monitor degeneration through the length of the nerve. The remaining nerve was homogenized in a small (1-ml) Kontes Duall tissue grinder at a concentration of $100 \mathrm{mg}$ (wet weight of tissue) $/ \mathrm{ml}$ of electrophoresis sample buffer (Laemmli, 1970). For experiments using two-dimensional gels, the nerves were homogenized in the "lysis buffer" of O'Farrell (1975), consisting of 9.5 M urea, 2\% Nonidet P-40, 5\% $\beta$-mercaptoethanol, but without Ampholines. Homogenates were either analyzed immediately or frozen at $-80^{\circ} \mathrm{C}$ until they could be analyzed. Similar results were obtained with both fresh and frozen material.

Electrophoresis. For analysis on SDS-polyacrylamide gels, samples were diluted in $1 \%$ SDS, $10 \mathrm{~mm}$ dithiothreitol (DTT), $20 \mathrm{~mm}$ Tris-HCl, pH 6.8 (Laemmli, 1970), heated at $100^{\circ} \mathrm{C}$ for $5 \mathrm{~min}$, and applied to the gels. For two-dimensional analysis, samples were applied to isoelectric focusing gels prepared according to O'Farrell (1975). Since the neurofilament proteins focus between $\mathrm{pH} 4.5$ and $\mathrm{pH}$ 6.5, the $\mathrm{pH}$ gradient was formed in this range. Ampholines (Bio-Rad) were added to the homogenates when they were diluted, prior to application to the isoelectric focusing gels. For analysis in the second dimension, as well as for one-dimensional analysis, 0.75mm-thick slab gels were formed with a gradient of $5 \%$ to $20 \%$ acrylamide. The buffer conditions were those of Laemmli (1970). Gels were stained with Coomassie blue R-250 and destained in $10 \%$ acetic acid and $20 \%$ methanol.

Electron microscopy. Small samples of degenerating and control nerves were fixed by immersion in glutaraldehyde/paraformaldehyde. The pieces of nerve, embedded in Spurr's water-soluble resin (1969), were oriented in order to allow transverse sectioning of the nerves. Sections were stained with uranyl acetate and lead citrate (Reynolds, 1963) and were examined and photographed in a Philips EM300 electron microscope, operating at $80 \mathrm{kV}$ and fitted with a $25-\mu \mathrm{m}$ objective aperture.

\section{Results}

Degeneration of optic nerve. The process of Wallerian degeneration has been documented extensively in various parts of the nervous systems of many different vertebrate species. In the sciatic nerve, the destruction of axonal cytoplasm extends over the length of the distal part of the nerve within a matter of a few days (see, for example, Donat and Wisniewski, 1973). Wallerian degeneration is a much slower process in the optic nerves (Ramon $y$ Cajal, 1928; McCaman and Robins, 1959a, b; Perez et al.,
1970; Cook and Wisniewski, 1973). Although we could be confident, on the basis of published studies, that 1 or 2 weeks after sciatic nerve section, virtually all of the axons had degenerated distal to the cut, it was necessary to ascertain that this was true for the optic nerve.

The typical organization of intact optic nerve is seen in Figure 1. The nerve is formed of myelinated axons surrounded by processes of glial cells including many fibrous astrocytes containing glial filaments. The axial cytoskeletal elements of the axons-microtubules and neurofilaments-are common features of these axons (Fig. 1b); microtubules are also axial components of some glial processes (Fig. 1b). Two weeks after nerve section, nearly all axons are disrupted extensively. The axoplasm is condensed and axonal cytoskeletal structures are rarely observed (Fig. 2). Although there are extensive ramifying processes of fibrous astrocytes extending between and around bundles of axons in the control nerves (Fig. 1), these are an even more prominent feature of the degenerating nerves (Figs. 2 and 3). Large bundles of filaments abound in cytoplasmic processes which surround nearly every degenerating axon.

The sciatic nerve degenerates much more quickly. Fine structure changes in sciatic degeneration have been described by many investigators (see, for example, Donat and Wisniewski, 1973). Morphological examination of each sciatic nerve used in this study confirmed advanced Wallerian degeneration of the sectioned nerves and essentially no detectable axoplasmic structures in these nerves.

Protein changes in oplic nerve. In preliminary studies, we focused on the optic nerve with results that were consistent with those reported by Schlaepfer and Micko for rat sciatic nerve (Schlaepfer and Micko, 1978). One week after enucleation, there was little detectable change in the distribution of protein as visualized on one-dimensional gels. After 2 weeks, the most prominent change was the diminution of three bands at positions corresponding to molecular weights of 68,000 (P68), 150,000 (P150), and 200,000 (P200) daltons, the triplet proteins of neurofilaments.

In Figure 4, the SDS-gel patterns of three pairs of nerves are compared. These are 1, 2, and 4 weeks after enucleation. In each case, the sectioned nerve is compared to the intact nerve from the same animal. One week after nerve section, there was a reduction in P200, whereas the other triplet proteins were barely affected. Two and 4 weeks after nerve section, P200 and P150 were undetectable and $\mathrm{P} 68$ was reduced markedly. ${ }^{3}$ Even on heavily overloaded gels (Fig. 5, tracks 5 to 8 ), the triplet polypeptides appeared to be the only bands clearly reduced after nerve section. 'There was some reduction in bands at low molecular weights; these are probably myelin proteins. Densitometric scanning of the one-dimensional gels confirmed the diminution of the neurofilament proteins (Fig. 6). There was some suggestion that the 50,000-dalton protein is also reduced.

\footnotetext{
${ }^{3}$ In Figure 4, tracks 6 and 8, there are prominent bands with apparent molecular weights of about 70,000 daltons. Bands in this position have never been found to increase in any of our other degeneration experiments.
} 

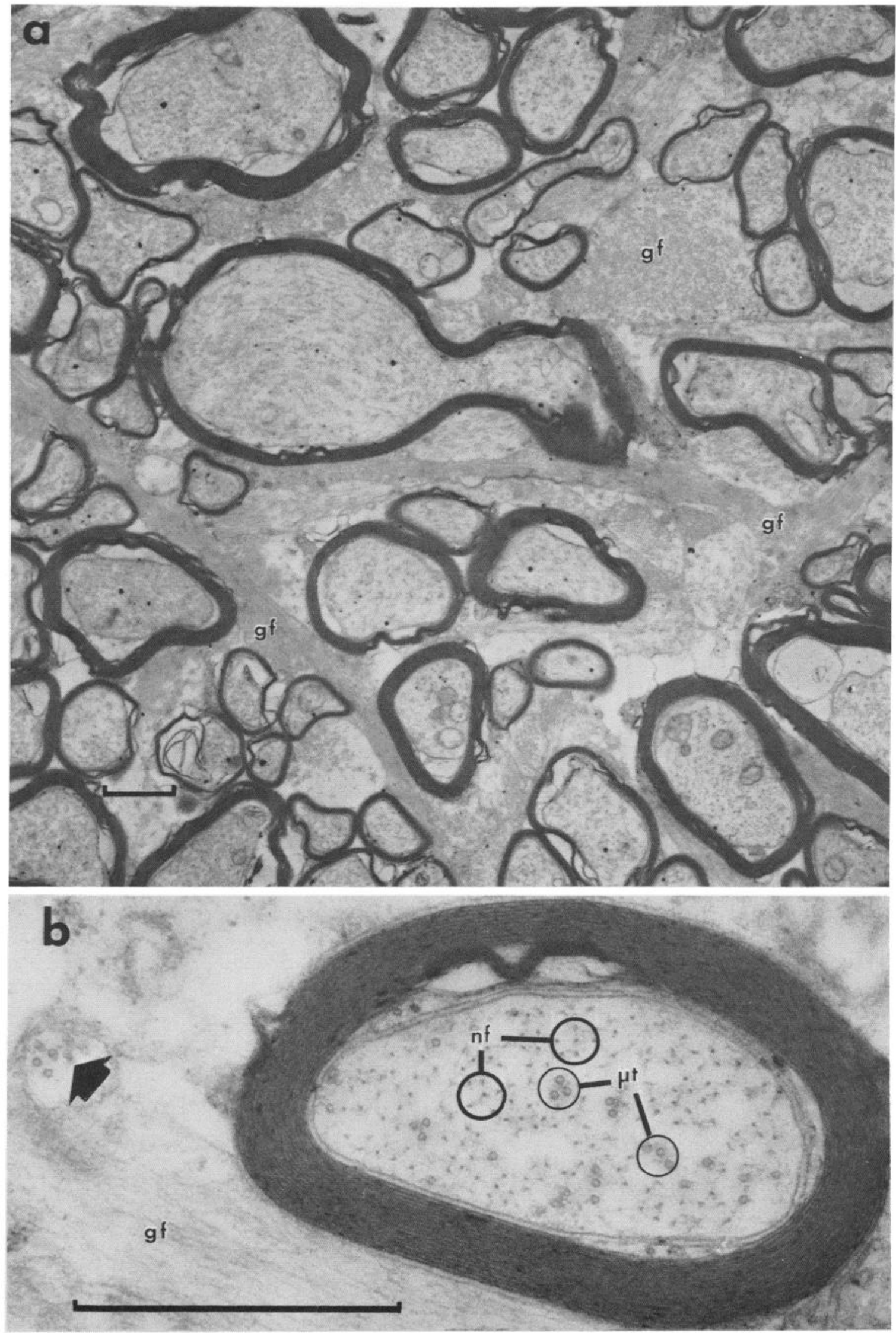

Figure 1. $a$, Section of immersion-fixed control optic nerve. Typical axial axonal structures are seen, especially microtubules and neurofilaments. Despite fixation artifacts, organization of myelin is evident. Glial processes filled with filaments ( $g f$ ) surround axons. $b$, A myelinated axon and surrounding glial processes from control optic nerve. Note neurofilaments $(n f)$ and microtubules $(\mu t)$ in axon, glial filaments $(g f)$, and microtubules (arrow) in a glial process. Magnification bar $=1 \mu \mathrm{m}$. 


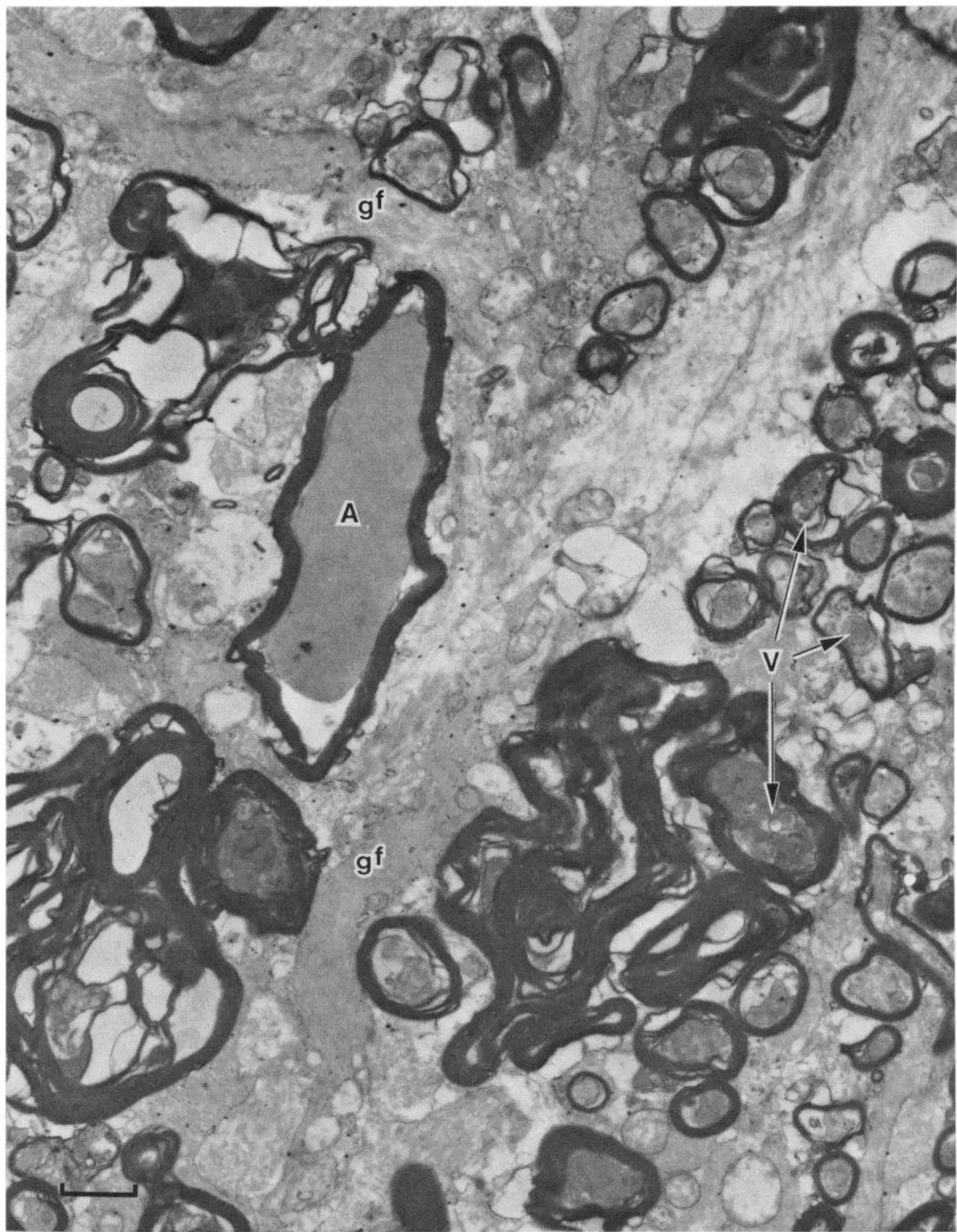

Figure 2. Optic nerve 2 weeks after enucleation. Severely disrupted axons are common. Many include electron-dense, amorphous material $(A)$ or dense vesicular structures $(V)$. Intact neurofilaments are not seen. Astrocytic processes $(g f)$ surround groups of degenerating axons. This section was taken about $3 \mathrm{~mm}$ anterior to optic chiasm. Magnification bar $=1 \mu \mathrm{m}$.

On two-dimensional gels, the proteins are resolved into many spots. For example, on a gel from a control optic nerve, the material migrating with an apparent molecular weight of 50,000 daltons (P50) includes as many as 10 spots (Fig. 7a). Other prominent groups of spots include a doublet at about 60,000 daltons (P60) and spots at 68,000 and 150,000 daltons. A faint smear is resolved at 200,000 daltons. A comparison of these proteins with isolated central nervous system (CNS) 10-nm filaments (prepared according to Czosnek et al., 1980) shows that 


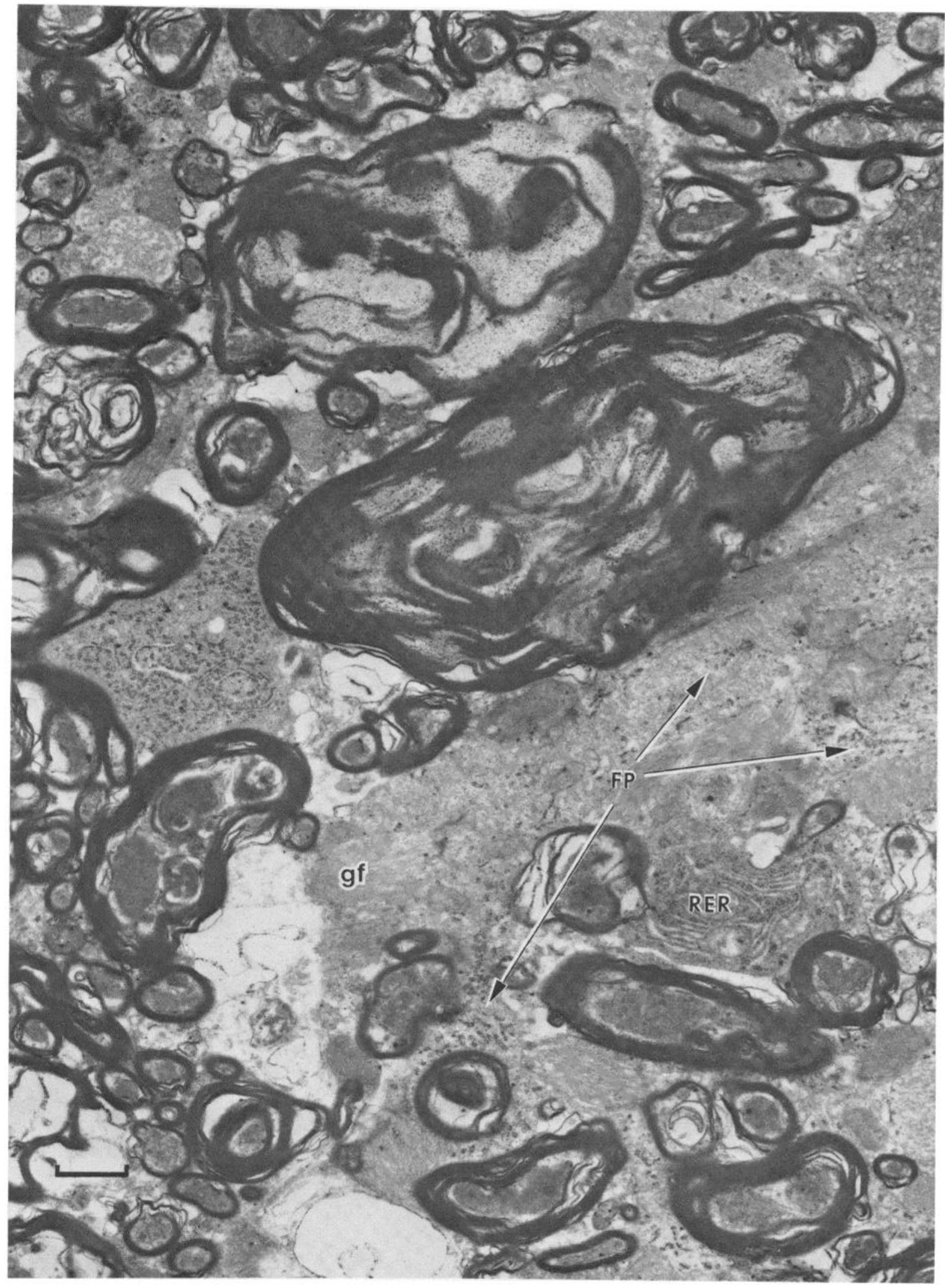

Figure 3. Optic nerve 4 weeks after enucleation. Nearly all axons are degenerated extensively. Masses of fragmented myelin are common. Astrocytes are filled with filaments $(g f)$, extensive rough endoplasmic reticulum $(R E R)$, and large numbers of free polyribosomes $(F P)$. This section was taken about $3 \mathrm{~mm}$ anterior to optic chiasm. Magnification bar $=1 \mu \mathrm{m}$. 


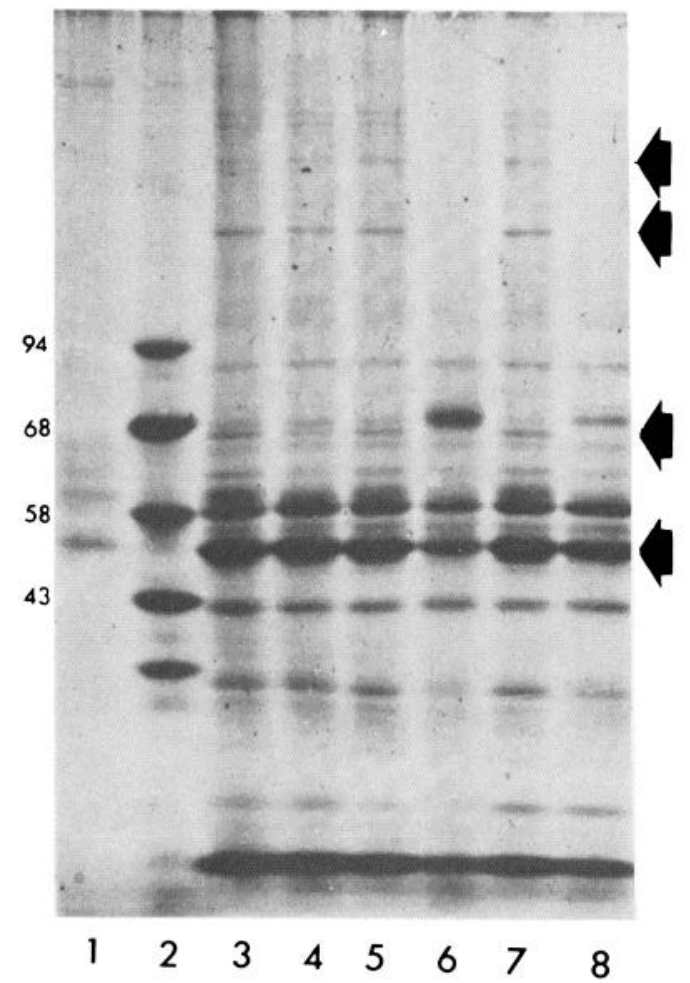

Figure 4. SDS-gel electrophoresis of optic nerve proteins 1, 2 , and 4 weeks after enucleation. Track 1, Microtubule protein; track 2, molecular weight standards (molecular weights indicated to the left of track 1); tracks 3 and 4, nerves after 1 week ( 3 , control; 4 , enucleated); tracks 5 and 6 , nerves after 2 weeks (5, control; 6 , enucleated); tracks 7 and 8 , nerves after 4 weeks (7, control; 8, enucleated). The positions of P200, P150, P68, and P50 are indicated by arrows. Eight micrograms of nerve protein were loaded in each well.

the $68,000-, 150,000-$, and 200,000 -dalton spots migrate to the same position as do the neurofilament triplet proteins, P68, P150, and P200 (Fig. $7 b$ ). Many other proteins are detectable on the two-dimensional gels of optic nerve, including a peptide which focuses at a pH of about 6 and has a molecular weight of about 65,000 daltons (P65) (Fig. $7 a$ ).

Eighteen days after nerve section, four proteins were absent from the sectioned optic nerves (Fig. 8). These included the neurofilament proteins and P65. The P200 protein is quite labile (Liem et al., 1978; Czosnek et al., 1980 ) and was often difficult to detect in filament preparations and in control tissue. There was no evidence for a loss of any of the 50,000-dalton polypeptides from the degenerating nerves.

Similar protein changes were seen when sectioned and control optic nerves were compared 4 weeks after nerve section (Fig. 9). In this figure, $50 \mu \mathrm{l}$ of nerve homogenate were applied to the isoelectric focusing gels. With this large amount of protein, $2 \frac{1}{2}$ times that applied to the gels in Figure 8, there is distortion of some of the P50 spots, but resolution of multiple forms of $\mathrm{P} 150$ is now possible (see Czosnek et al., 1980). It is evident from this analysis that the neurofilament proteins and $\mathrm{P} 65$ are missing from the degenerated nerve.

Protein changes in sciatic nerve. SDS-gel analysis of sciatic nerve is complicated by the presence of a large

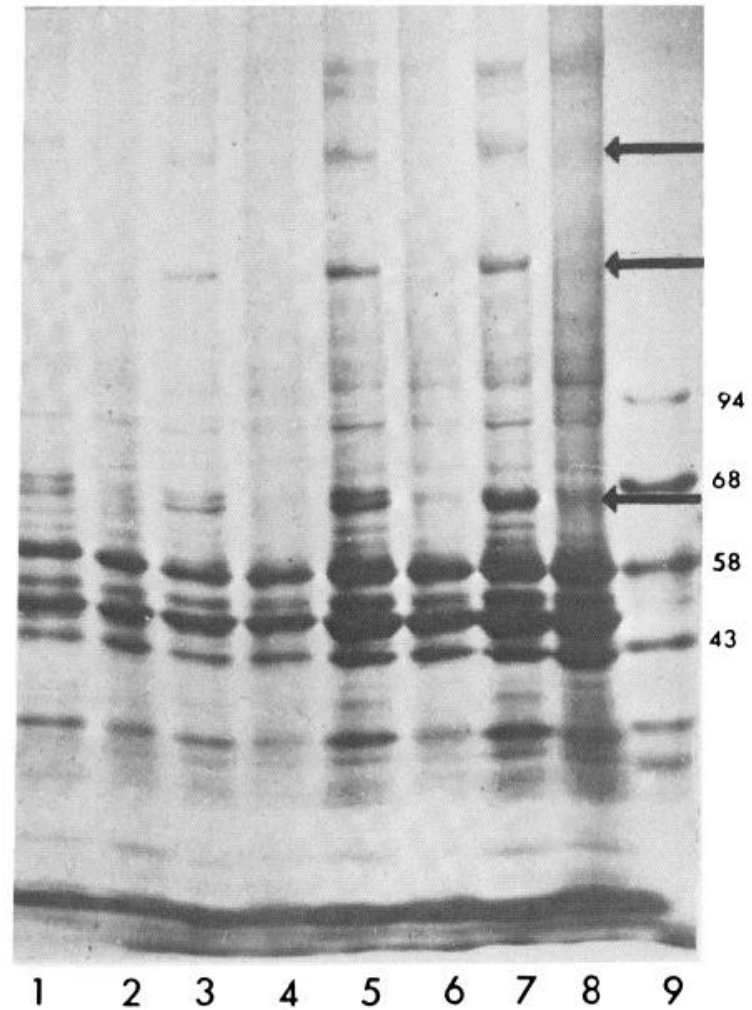

Figure 5. SDS-gel electrophoresis of optic nerve proteins 2 weeks after enucleation. Tracks 1 to 8 : Control $(1,3,5,7)$ and degenerated $(2,4,6,8)$ nerves. Pairs of tracks represent application of equal amounts of homogenate to gel. Thus, tracks 1 and 2 had $8 \mu \mathrm{g}$ of protein, 3 and 4 had $10 \mu \mathrm{g}$ of protein, 5 and 6 had $20 \mu \mathrm{g}$ of protein, and 7 and 8 had $30 \mu \mathrm{g}$ of protein. Track 9 , Molecular weight standards.

amount of a 68,000 -dalton protein. On two-dimensional gels, this protein is separated from most of the other proteins of interest (Fig. 10). Comparison with the twodimensional gel pattern of rabbit serum (Fig. 10c) shows that the 68,000 -dalton major protein of sciatic nerve and rabbit serum albumin migrate to the same positions and are probably the same protein. The focusing of the serum albumin-like protein at a $\mathrm{pH}>6$ clearly separates this protein from the P68 of sciatic neurofilaments (Fig. 10a). On two-dimensional gels of degenerated sciatic nerve, the three neurofilament proteins and the $\mathrm{P} 65$ protein are the only spots absent. The P60 protein appears as a less significant component of sciatic nerve than of optic nerve only because the albumin is such a prominent constituent of the sciatic nerve protein. Two-dimensional analyses of pairs of sciatic nerves-one degenerated, the other control-demonstrate that the same four proteins (P65, P68, $\mathrm{P} 150$, and $\mathrm{P} 200$ ) that disappear in degenerating optic nerve also disappear in degenerating sciatic nerve. The sciatic nerve lacks P50 but includes prominent spots which appear to co-migrate with actins. These actin-like spots are not affected by degeneration.

\section{Discussion}

Wallerian degeneration of optic nerve occurs more slowly than Wallerian degeneration of sciatic nerve, but the sequence of events differs little. In both nerves, the 


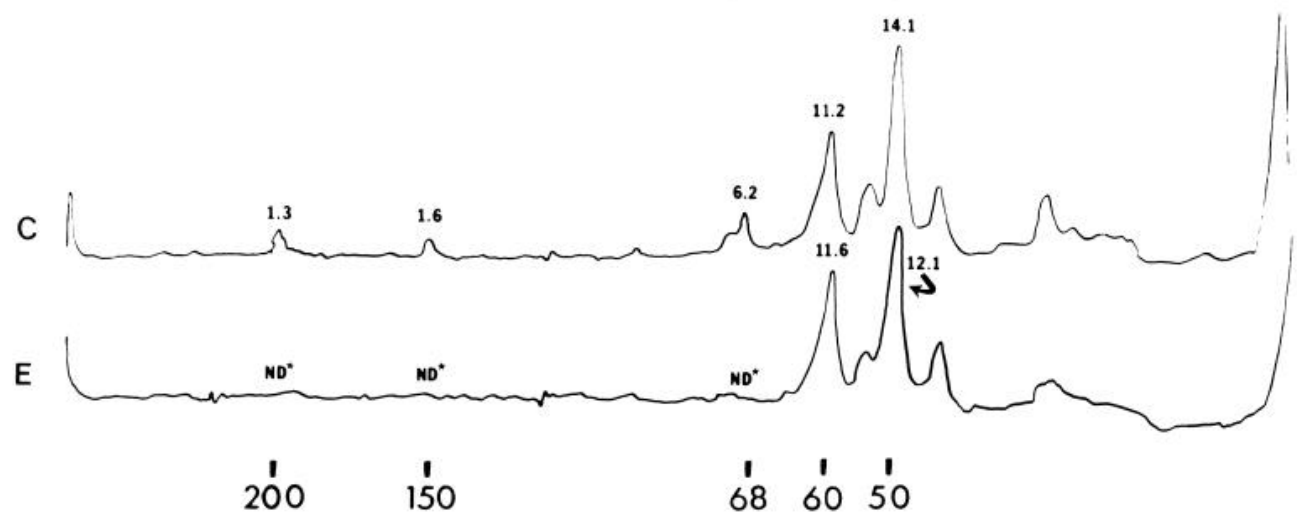

Figure 6. Densitometric tracings of Coomassie blue-stained SDS-gels of homogenates of control $(C)$ and degenerating $(E)$ optic nerves 2 weeks after nerve section. The numbers above the tracings refer to the percentage of total protein under each peak. Quantitation was both by integration and by cutting out the tracing and weighing the peaks. $N D^{*}$ means the peak was too small to be measured. The numbers below the tracings indicate the positions of proteins discussed in the text and give their apparent molecular weights in kilodaltons. These tracings are of tracks 3 and 4 in Figure 5.
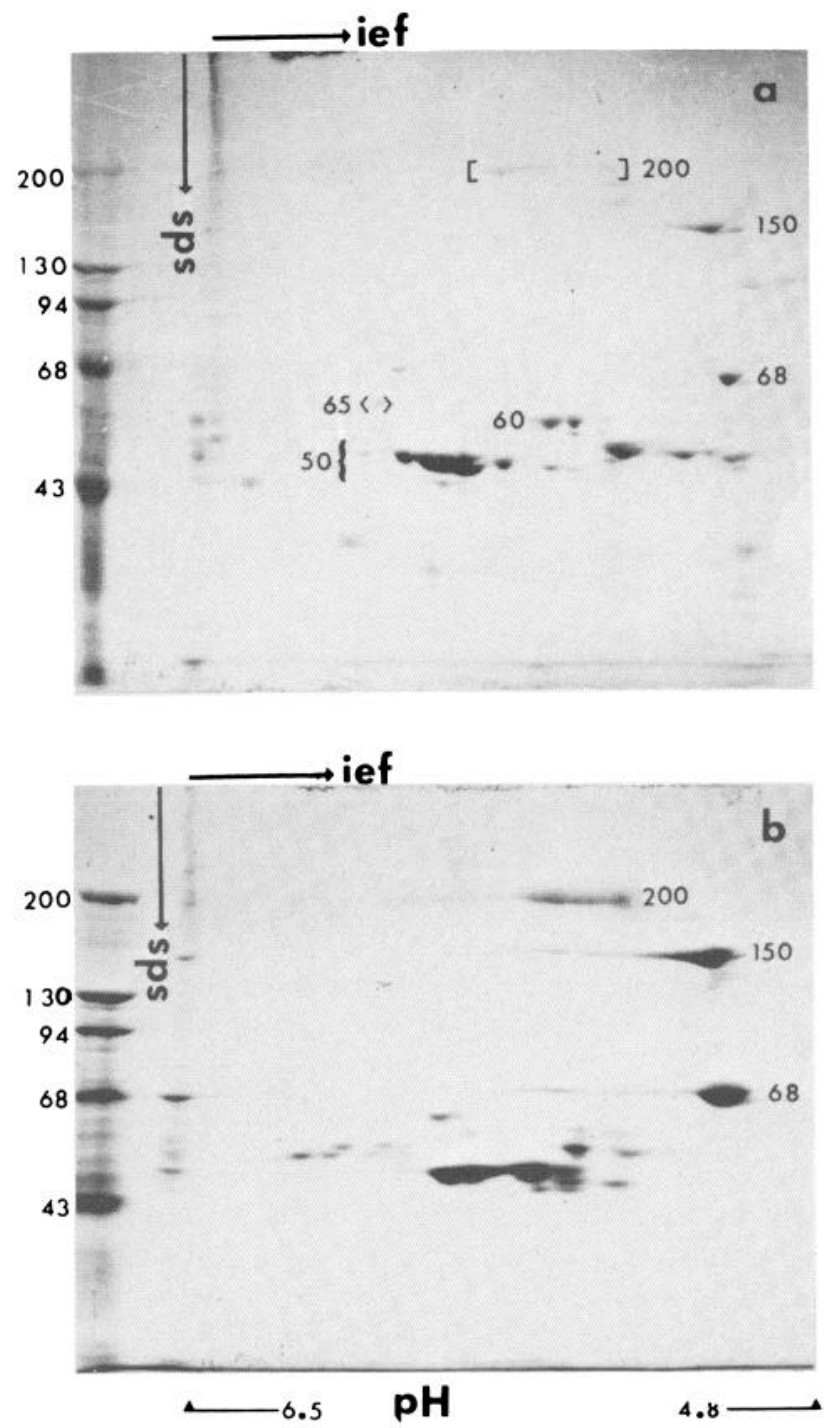

Figure 7. Two-dimensional electrophoresis of optic nerve homogenate $(a)$ and spinal cord 10-nm filament preparation (b). Filaments were prepared according to Czosnek et al. (1980). Standard proteins were run in the second dimension. Their molecular weights are indicated on the left. In $a$, the positions axons are the site of the first signs of degeneration. The axonal cytoplasm undergoes a series of changes during which the axial cytoskeletal structures break down. The neurofilaments and microtubules are replaced by floccular material which eventually forms a mass of amorphous electron-opaque material in place of the axoplasm (see also Donat and Wisniewski, 1973; Schlaepfer and Micko, 1978). The myelin degenerates more slowly than the axoplasm, but, at the times that we have used in these experiments, the major myelin proteins do appear to be reduced.

Both optic nerve and sciatic nerve were included in these studies to resolve the problem of whether there is a major axon-specific protein with a molecular weight of about 50,000 daltons. Most of the complex of 50,000dalton proteins of nerve is presumed to originate from fibrous astrocytes which are lacking in sciatic nerve. As has been shown recently (Schlaepfer et al., 1979), homogenates of human and bovine sciatic nerve lack a major 50,000-dalton band on SDS-gels. If there are detectable amounts of neuron-specific protein with this molecular weight, the 50,000 -dalton protein should be seen on two-dimensional gels of sciatic nerve as well as optic nerve and should disappear when the axons degenerate. No such protein has been detected. In fact, only four constituent polypeptides of both nerves are absent from two-dimensional electropherograms of degenerating nerves. Three of these correspond to the neurofilament proteins, while the fourth, which has not been identified yet, has an apparent molecular weight of about 65,000 daltons and is termed P65. There were some apparent variations in other proteins, but these were not consistent from one preparation to another.

of the various proteins discussed in the text are indicated with the numerical values of their apparent molecular weights in kilodaltons. The spots that form the 50,000-dalton band on onedimensional gels are grouped collectively and marked 50 . In $b$, the positions of authentic neurofilament proteins are indicated for comparison with $a$. The directions of isoelectric focusing (ief) in the first dimension, and SDS-gel electrophoresis (sds) in the second dimension are indicated by arrows. 

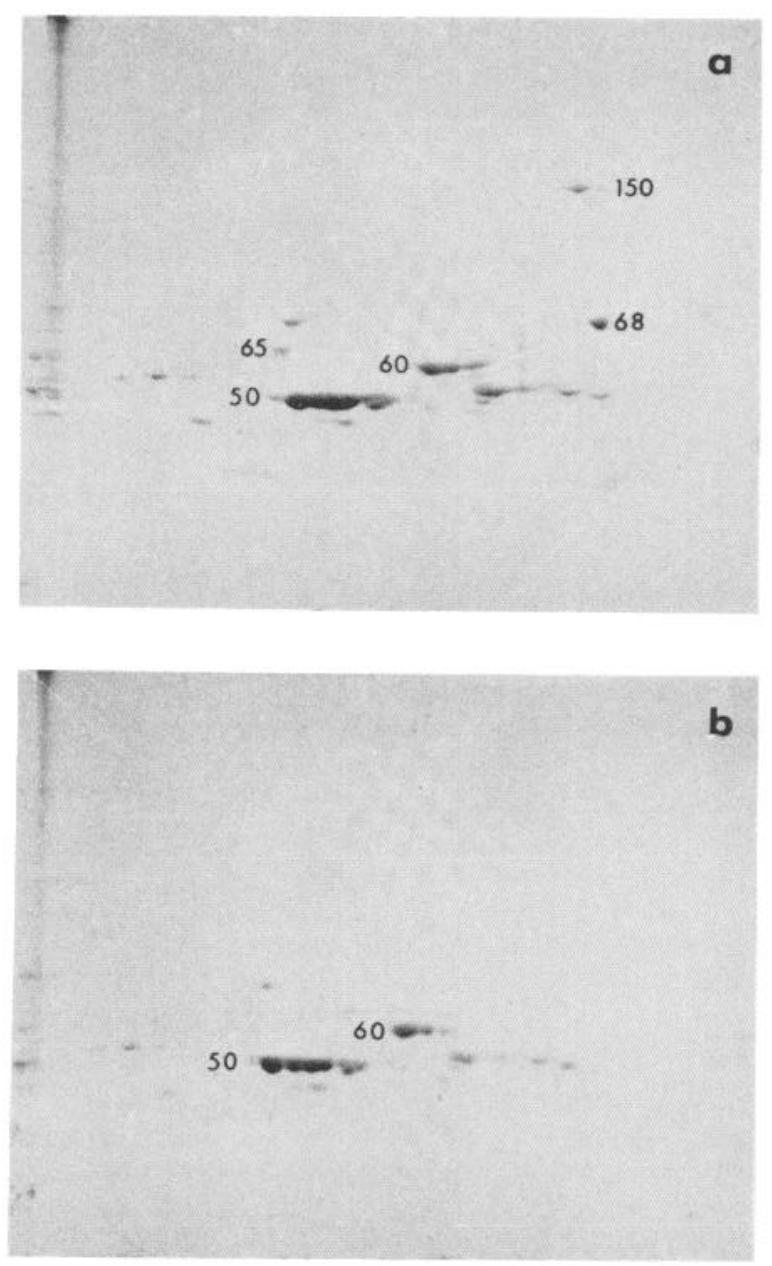

Figure 8. Two-dimensional gel analysis of control $(a)$ and degenerating $(b)$ optic nerves 18 days after enucleation. Twenty microliters of nerve homogenate were applied to the isoelectric focusing gel. The gels are marked as in Figure 7.

The Coomassie blue staining of protein spots on these thin $(0.75-\mathrm{mm})$ slab gels will only detect proteins present in amounts greater than about $0.2 \mu \mathrm{g} / \mathrm{spot}$. There are undoubtedly enzymes and regulatory proteins which are neuron-specific but are present in amounts too small to be detected by this procedure. If they could be detected by immunochemical means, this sort of analysis could be extended to include them. However, for such detection to be possible, each protein must be identified first. In the case of the major protein constituents of the nerve, prior identification is not necessary. The spectrum of demonstrable polypeptides is examined and analyzed to determine experimentally induced alterations in those proteins which are present in sufficient quantity to bind measurable amounts of Coomassie blue.

The four proteins that disappear in parallel with axonal degeneration include three (P200, P150, and P68) which have the same distribution on two-dimensional gels as do the triplet proteins of neurofilaments (Czosnek and Soifer, 1980; Czosnek et al., 1980). They are identified as the neurofilament proteins not only on this basis but also because their disappearance from the gels parallels the morphologic changes, the disappearance of the filaments
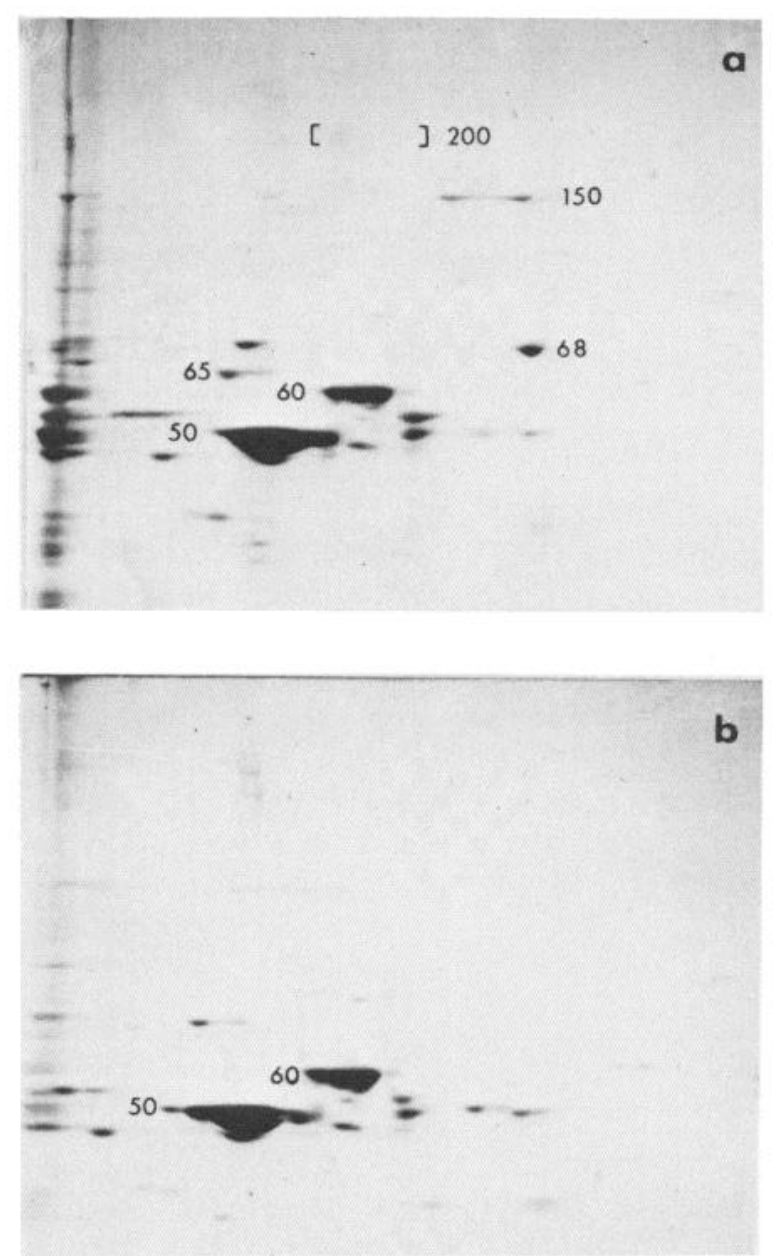

Figure 9. Two-dimensional gel analysis of control $(a)$ and degenerating $(b)$ optic nerves 4 weeks after enucleation. Fifty microliters of nerve homogenate were applied to the isoelectric focusing gel. The gels are marked as in Figure 7.

from the degenerating neurons (see also Schlaepfer and Micko, 1978). The P65 is not a component of filament preparations (Czosnek et al., 1980; Czosnek and Soifer, 1980) and should prove to be another useful neuronspecific probe.

In experiments in which one-dimensional SDS slab gels were used to compare degenerating optic nerves with controls, a small decrease in the amount of P50 was found in the degenerating nerves. Analysis on two-dimensional gels demonstrated that this decrease in P50 was not due to the loss of one of the many polypeptides with molecular weights near 50,000 daltons. If there was a partial loss of several isomorphic polypeptides from the P50 region, the decrease would not be detectable by this approach unless it was very large. What is demonstrated here is that none of the 50,000-dalton polypeptides which focus in the range of the $\mathrm{pH}$ gradient and which include isomorphs of glial fibrillary acidic protein (L. F. Eng, personal communication) disappear from the optic nerve when the axons degenerate. Two-dimensional gel analyses using $\mathrm{pH}$ gradients of broader range (4 to 8.5) did not show any additional neuron-specific proteins. The narrow $\mathrm{pH}$ range was used for most experiments because of 

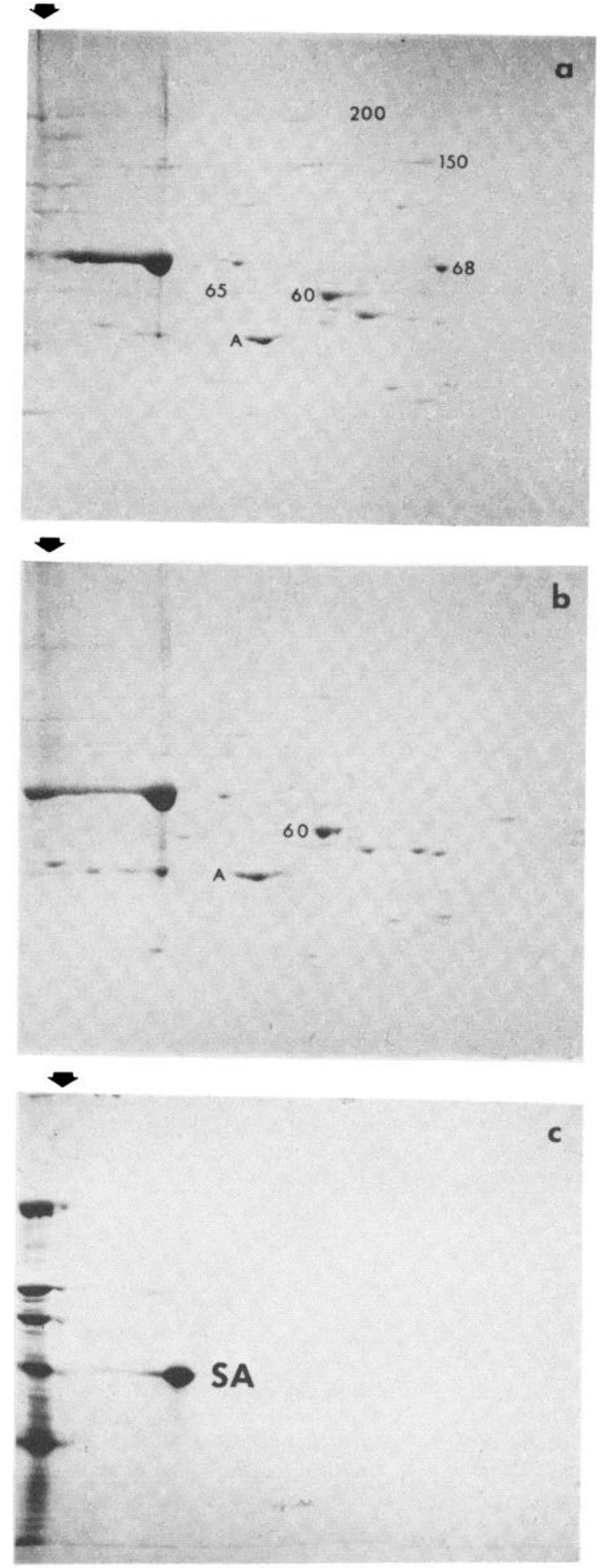

Figure 10. Two-dimensional gel analysis of control $(a)$ and degenerating $(b)$ sciatic nerves 18 days after section. $A$ marks the locus of the actin-like spots. Gel $c$ is a two-dimensional gel of rabbit serum. The bands on the left are molecular weight standards as in Figure 7. Arrows at the tops of each gel mark the origin. The gels are marked as in Figure 7. $S A$, serum albumin. the high resolution resulting from spreading the proteins of interest across the gel.

Not only axonal proteins but also myelin proteins break down as the nerve degenerates. As is evident from the material in Figure 3, considerable myelin remains in optic nerve even 4 weeks after nerve section, although myelin proteins are reduced. The myelin basic proteins are not demonstrable in the two-dimensional gel system because their $\mathrm{pI}$ is more basic than the alkaline limit of the $\mathrm{pH}$ gradient.

The demonstration of the loss of four neuron-specific proteins from degenerating nerve suggests a useful assay to detect axonal damage in degenerative diseases. Not only are human neurofilaments formed of a triplet of polypeptides similar to those of rabbits (Davison and Jones, 1980) but they have a similar distribution of polypeptides on two-dimensional gels $(\mathrm{H}$. Czosnek and D. Soifer, unpublished observation). Recent observations from this department (H. M. Wisniewski, D. Soifer, H. Czosnek, K. Mack, K. Iqbal, and K. Wisniewski, submitted for publication; K. Wisniewski, H. Czosnek, H. M. Wisniewski, D. Soifer, P. Ramos, K. S. Kim, and K. Iqbal, submitted for publication) indicate that, in the case of disease-induced neuronal loss, there is a selective loss of the triplet polypeptides. Since as little as $20 \mathrm{mg}$ of tissue are required for these experiments, these results strongly suggest the utility of the gel analysis of filament proteins in the study of neuronal pathology.

\section{References}

Cook, R. D., and H. M. Wisniewski (1973) The role of oligodendroglia and astroglia in Wallerian degeneration of the optic nerve. Brain Res. 61: 191-206.

Czosnek, H., and D. Soifer (1980) Comparison of the proteins of $10 \mathrm{~nm}$ filaments from rabbit sciatic nerve and spinal cord by electrophoresis in two dimensions. FEBS Lett. 117: 175178.

Czosnek, H., D. Soifer, and H. M. Wisniewski (1980) Heterogeneity of intermediate filament proteins from rabbit spinal cord. Neurochem. Res. 5: 777-793.

Dahl, D., and A. Bignami (1975) Protein differences associated with the loss of myelinated axons and fibrillary gliosis in rat optic nerves following Wallerian degeneration. FEBS Lett. 51: 313-316.

Davison, P. F., and R. N. Jones (1980) Neurofilament proteins of mammals compared by peptide mapping. Brain Res. 182: $470-473$.

Donat, J. R., and H. M. Wisniewski (1973) The spatio-temporal pattern of Wallerian degeneration in mammalian peripheral nerves. Brain Res. 53: 41-53.

Hoffman, P. N., and R. J. Lasek (1975) The slow component of axonal transport. Identification of major structural polypeptides of the axon and their generality among mammalian neurons. J. Cell Biol. 66: 351-366.

Joseph, B. S. (1973) Somatofugal events in Wallerian degeneration: A conceptual overview. Brain Res. 59: 1-18.

Laemmli, U. K. (1970) Cleavage of structural proteins during assembly of the head of bacteriophage $\mathrm{T}_{4}$. Nature 227: 680685.

Liem, R. K. H., S. -H. Yen, G. D. Salomon, and M. L. Shelanski (1978) Intermediate filaments in nervous tissues. J. Cell Biol. 79: 637-645.

McCaman, R. E., and E. Robins (1959a) Quantitative biochemical studies of Wallerian degeneration in the peripheral and 
central nervous systems-I: Chemical constituents. J. Neurochem. 5: 18-31.

McCaman, R. F., and F. Robins (1959b) Quantitative biochemical studies of Wallerian degeneration in the peripheral and central nervous systems-II: Twelve enzymes. J. Neurochem. 5: 32-42.

O'Farrell, P. H. (1975) High resolution two-dimensional electrophoresis of proteins. J. Biol. Chem. 250: 4007-4021.

Perez, V. J., J. W. Olney, T. J. Cicero, B. W. Moore, and B. A. Bahn (1970) Wallerian degeneration in rabbit optic nerve: Cellular localization in the central nervous system of the S100 and 14-3-2 proteins. J. Neurochem. 17: 511-519.

Ramon y Cajal, S. (1928) Degeneration and Regeneration of the Nervous System, Vol. II, Oxford University Press, London.

Reynolds, E. S. (1963) The use of lead citrate at high $\mathrm{pH}$ as an electron opaque stain in electron microscopy. J. Cell Biol. 17: 208-212.

Scheele, G. A. (1975) Two-dimensional gel analysis of soluble proteins. Characterization of guinea pig exocrine pancreatic proteins. J. Biol. Chem. 250: 5375-5385.

Schlaepfer, W. W., and S. Micko (1978) Chemical and structural changes of neurofilaments in transected rat sciatic nerve. $\mathrm{J}$. Cell Biol. 78: 369-378.

Schlaepfer, W. W., L. A. Freeman, and L. F. Eng (1979) Studies of human and bovine spinal nerve roots and the outgrowth of CNS tissues into the nerve root entry zone. Brain Res. 177: 219-229.

Soifer, D., K. Iqbal, J. A. Sturman, and H. M. Wisniewski (1978) Protein changes in rabbit optic nerve following enucleation. J. Cell Biol. 79 (2, Part II): 279a.

Spurr, A. R. (1969) A low viscosity epoxy resin embedding medium for electron microscopy. J. Ultrastruct. Res. 26: 3143.

Waller, A. V. (1850) Experiments on the section of the glossopharyngeal and hypoglossal nerves of the frog, and observations of the alterations produced thereby in the structure of their primitive fibers. Philos. Trans. R. Soc. Lond. (Biol.) 140: $423-429$. 